\title{
Elimination of Methane from Protonated Acetaldehyde: The Ab Initio Transition State
}

\author{
Charles E. Hudson, Liberty DeLeon, Don Van Alstyne, and \\ David J. McAdoo \\ Marine Biomedical Institute, The University of Texas Medical Branch, Galveston, Texas USA
}

\begin{abstract}
The transition state (TS) for loss of $\mathrm{CH}_{4}$ from protonated acetaldehyde has been located at the second-order Moller-Plesset (MP2) /6-31G $(d, p)$ level of theory. The activation energy is predicted to be $263.9 \mathrm{~kJ} / \mathrm{mol}$ starting from the more stable form (methyl and hydrogen $E$ ) and $261.6 \mathrm{~kJ} / \mathrm{mol}$ starting from the less stable form (methyl and hydrogen $\mathrm{Z}$ ) that is required for reaction. The products (methane and the formyl ion) are predicted to lie $136.6 \mathrm{~kJ} / \mathrm{mol}$ below the TS for their formation. MP2 methods underestimate the heats of formation of both the TS and the reaction products by about $40 \mathrm{~kJ} / \mathrm{mol}$ when compared with experiment. Restricted Hartree-Fock (RHF) calculations give much more accurate relative energies. The MP2 TS leads directly to fragmentation and is described as a protonation of the methyl group by the acidic proton on oxygen. Under RHF theory the reaction is stepwise. An RHF TS similar to the MP2 TS leads to a nonclassical intermediate (which is stable at this level of theory) that has one of the $\mathrm{C}-\mathrm{H}$ bonds protonated. This mechanism (protonation of an alkyl group) appears to be a general one for high energy 1,2 eliminations from organic cations. (J Am Soc Mass Spectrom 1994, 5, 1102-1106)
\end{abstract}

$\mathrm{T}$ The loss of alkanes from metastable odd electron ions is well described as occurring by hydrogen abstraction by the radical in ion-radical complexes [1-4]. However, alkane loss also takes place from even-electron precursors. Much of the evidence for complexes does not apply to even-electron systems, because such ions usually do not dissociate to radicals at the low energies typical of metastable ions. A concerted 1,2 elimination from an even-electron ion is also expected to be a high energy process [5]. Therefore, to characterize the elimination of methane from an evenelectron ion, we used quantum mechanics to understand the loss of $\mathrm{CH}_{4}$ from protonated acetaldehyde (1). $\mathrm{C}_{2} \mathrm{H}_{5} \mathrm{O}^{+}$ions have long been of interest, as an early seminal study [6] demonstrated that the shapes and relative abundances of peaks produced by the metastable dissociations of these ions could be used to identify the structures of the dissociating species. Keyes and Harrison [7] demonstrated that several mechanisms are operative in the loss of methane from protonated acetaldehyde by using $70-\mathrm{cV}$ ionization, but that the lowest energy process produces methane that contains the methyl carbon and the hydrogen on oxygen, and it has one of the two lowest transition states leading to fragmentation of 1 . (The other leads to formation of $\mathrm{H}_{3} \mathrm{O}^{+}$[7].)

Address reprint requests to $\mathrm{C}$. E. Hudson, University of Texas Medical Branch, Marine Biomedical Institute, 200 University Boulevard, Galveston, Texas 77555-0843.

\section{Facilities and Methods}

All structures were fully optimized at the MP2/6$31 G(d, p) *$ level with frozen core (ignores excitations out of the $1 \mathrm{~s}$ orbitals of $\mathrm{C}$ and $\mathrm{O}$ ) by using GAUSSIAN 92 [8] as implemented on the Cray Y-MP computer at The University of Texas Center for High Performance Computing. All structures were confirmed as minima or proper transition states (TSs) by vibrational frequency calculations. There is a single imaginary wave number of $318 \mathrm{i} / \mathrm{cm}$ in the Moller-Plesset (MP2) TS and $826 \mathrm{i} / \mathrm{cm}$ in the restricted Hartree-Fock (RHF) TS. The TS finding routine [opt $=$ (ts,calcall)] was begun with a structure of no symmetry; however, the optimized structure has a plane of symmetry. Mulliken charges and overlap populations were computed from the self-consistent hield (SCF) density, which is the default option even when the energy is computed with MP2 methods. The search for the Hartree-Fock (HF) TS began with unrestricted Hartree-Fock (UHF) methods. However we soon noticed that the faster RHF methods gave identical results in trial structures. Con-

\footnotetext{
*MP2 refers to second order Moller-Plesset theory. The G refers to the orbitals of gaussian form employed by the program. Ihus b$31 G(d, p)$ describes a sel of gaussian functions consisting of six in fixed ratio for the 15 orbitals on $C$ and $O$, three in fixed ratio to describe the valence arbitals (a $2 \mathrm{~s}$ and three $2 p$ orbitals for $\mathrm{C}$ and $\mathrm{O}$ and a $1 \mathrm{~s}$ orbital for cach $H$ ), and a fourth for cach valence orbital whose ratio to the other three is chosen to minimize the energy. The $(d, p)$ signifies a set of $d$ orbitals on each $C$ and $O$ and a set of $p$ orbitals on each $\mathrm{H}$
} 
Table 1. Energies of relevant species ${ }^{a}$

\begin{tabular}{|c|c|c|c|c|}
\hline Species & Energy ${ }^{\circ}$ & $\begin{array}{c}\text { ZPVE }^{\mathrm{c}} \\
(\mathrm{kJ} / \mathrm{mol})\end{array}$ & $\begin{array}{c}E(\text { rel })^{\mathrm{d}, \mathrm{e}} \\
\{\mathrm{kJ} / \mathrm{mol})\end{array}$ & $\begin{array}{c}E(r e l, e x p t)^{d} \\
(\mathrm{~kJ} / \mathrm{mol})\end{array}$ \\
\hline \multirow[t]{2}{*}{$E-1$} & -153.685698 & 185.1 & 0.0 & $0.0^{\prime}$ \\
\hline & -153.241847 & 171.3 & 0.0 & 0.0 \\
\hline \multirow[t]{2}{*}{$Z-1$} & -153.684875 & 185.3 & 2.4 & -- \\
\hline & -153.240910 & 171.6 & 2.8 & \\
\hline \multirow[t]{2}{*}{ TS } & -153.577969 & 166.2 & 263.9 & $305^{9}$ \\
\hline & -153.113874 & 154.0 & 318.4 & \\
\hline \multirow[t]{2}{*}{$\mathrm{HCO}^{+}$} & -113.264833 & 42.6 & & \\
\hline & -112.969006 & 41.7 & & \\
\hline \multirow[t]{2}{*}{$\mathrm{CH}_{4}$} & -40.364626 & 122.2 & & \\
\hline & -40.202131 & 110.4 & & \\
\hline \multirow[t]{2}{*}{$\mathrm{CH}_{4}+\mathrm{HCO}^{+}$} & -153.629459 & 164.8 & 125.4 & $168.1^{\dagger}$ \\
\hline & -153.171137 & 152.1 & 166.4 & \\
\hline $2^{h}$ & -153.116597 & 155.8 & 313.3 & \\
\hline
\end{tabular}

"Upper number for each structure optimized at MP2/6-3†G(d,p) level; lower number optimized at $\mathrm{RHF} / 6 \cdot 31+\mathrm{G}(d, o)$ level.

${ }^{\mathrm{b}}$ Electronic energy in hartrees.

${ }^{\circ}$ Computed ZPVE for MP2 calculations; computed ZPVE $\times 0.89$ for RHF calculations.

${ }^{\mathrm{d}}$ Relative to $E-1$.

OOur calculations, including ZPVE.

'From ref 11.

${ }^{9}$ From ref 9

"HF only.

sequently the remainder of the work with HF methods employed RHF theory. The products reached via the TSs we obtained were assessed by adding 0.1 times the displacements calculated for the imaginary vibration to the coordinates of the TS in the direction that led to products and reoptimizing with opt $=$ calcall. Although the nonclassical structure (2) that results from the RHF TS was found with RHF methods, its wave function was shown to be stable under UHF theory. A UHF run with the command stable $=$ opt at the geometry of 2 gave the same energy as the RHF method.

\section{Results and Discussion}

The energies of all species calculated in this work are given in Table 1. Our MP2 calculations predict an activation energy of $263.1 \mathrm{~kJ} / \mathrm{mol}$ starting with the more stable $E$ (entgegen or trans) isomer of the reactant or $261.6 \mathrm{~kJ} / \mathrm{mol}$ starting with the $\mathrm{Z}$ (zusammen, or cis) isomer (the configuration required for reaction). The measured activation energy is $305 \mathrm{~kJ} / \mathrm{mol}$ [9]. However the authors of [9] argue that some of their appearance energies are too high. The products of the fragmentation are predicted by MP2 theory to have an energy $136.6 \mathrm{~kJ} / \mathrm{mol}$ below that of the TS.

The energy released in the dissociation depends on the precursor [10], but for ions generated initially as 1 , it is $42.3 \mathrm{~kJ} / \mathrm{mol}$ [10]. Combined with our calculated relative energies of these species, the implication is that $31 \%$ of the excess energy of the TS is liberated as kinetic energy of the products. The calculated difference in energy between the reactants and products is
Table 2. Optimized parameters of the $\mathrm{TS}^{a}$

\begin{tabular}{lrlrll}
\hline & Lengths $(\AA)$ & Angles (deg) & Dihedral angles (deg) \\
\hline RCO & 1.2202 & & & & \\
& 1.1902 & & & & \\
$\mathrm{RCC}$ & 1.5506 & $\mathrm{CCO}$ & 117.17 & & \\
& 1.5188 & & 113.19 & & \\
$\mathrm{ROH}$ & $\mathbf{1 . 8 0 3 5}$ & $\mathrm{HOC}$ & 66.95 & $\mathrm{HOCC}$ & 0.01 \\
& 1.6033 & & 75.26 & & 0.0 \\
$\mathrm{RCH} 1$ & 1.0896 & $\mathrm{H} 1 \mathrm{CC}$ & 113.51 & $\mathrm{H} 1 \mathrm{CCO}$ & 113.27 \\
& 1.0835 & & 115.72 & & 111.74 \\
$\mathrm{RCH} 2$ & 1.2214 & $\mathrm{H} 2 \mathrm{CC}$ & 118.11 & $\mathrm{H} 2 \mathrm{CCO}$ & 0.0 \\
& 1.2420 & & 111.51 & & 0.0 \\
$\mathrm{RCH} 3$ & 1.0896 & $\mathrm{H} 3 \mathrm{CC}$ & 113.52 & $\mathrm{H} 3 \mathrm{CCO}$ & -113.29 \\
& 1.0835 & & 115.72 & & -111.74 \\
$\mathrm{RCH} 4$ & 1.0931 & $\mathrm{H} 4 \mathrm{CO}$ & 126.51 & $\mathrm{H} 4 \mathrm{COHO}$ & 180.0 \\
& 1.0842 & & 125.96 & & 180.0 \\
\hline
\end{tabular}

${ }^{a}$ Upper number for each parameter is MP2/6-31G(d,p); lower number is $\mathbf{R H F} / \mathbf{6}-\mathbf{3} 1+\mathbf{G}(d, \rho)$.

$125.4 \mathrm{~kJ} / \mathrm{mol}$, which is substantially less than the experimental value of $168 \mathrm{~kJ} / \mathrm{mol}$ [11]. However this discrepancy does not affect the conclusion that $31 \%$ of the excess energy is released in the fragmentation, as the experimental values of the activation energy and of the product heats of formation are both about 40 $\mathrm{kJ} / \mathrm{mol}$ above our calculated values.

The optimized parameters of the TS are given in Table 2; they can be compared to those of $Z-1$ in Table 3. The distance matrix of the MP2 TS shows that the proton being transferred from oxygen to carbon is closer to both the carbonyl carbon $(1.737 \AA)$ and the methyl carbon $(1.254 \AA)$ than to the oxygen $(1.803 \AA)$. However it is closest of all to one of the methyl hydrogens, $112(0.895 \AA)$. The Mulliken charge on the migrating hydrogen is +0.353 , and is larger than that of any of the other hydrogens, which range from +0.266 to +0.328 . Thus the TS resembles a structure in which the acidic hydrogen has protonated the methyl group.

The extent of bond making and breaking in a TS can be qualitatively assessed by the interatomic distances involved. However the range of this variable (about 1 $\AA$ to infinity) lends itself poorly to a more quantitative understanding. We therefore used the overlap population (the sum of off-diagonal elements between atoms

Table 3. Optimized parameters of Z-1 [MP2/6-31G $(d, p)]$

\begin{tabular}{|c|c|c|c|}
\hline \multirow[t]{2}{*}{ Lengths $(\stackrel{A}{A})$} & \multirow[t]{2}{*}{ Angles (deg) } & \multicolumn{2}{|c|}{ Dihedral angles (deg) } \\
\hline & & & \\
\hline RCC 1.4587 & $\operatorname{cco} 125.95$ & & \\
\hline $\mathrm{ROH} 0.9816$ & HOC $\quad 114.26$ & HOCC & 0.00 \\
\hline $\mathrm{RCH} 11.0945$ & $\mathrm{H} 1 \mathrm{CC} 107.75$ & $\mathrm{H} 1 \mathrm{CCO}$ & -123.21 \\
\hline $\mathrm{RCH} 21.0864$ & $\mathrm{H} 2 \mathrm{CC} 114.846$ & $\mathrm{H} 2 \mathrm{CCO}$ & 0.03 \\
\hline RCH3 1.0945 & НзСC 107.75 & $\mathrm{HaCCO}$ & 123.29 \\
\hline $\mathrm{RCH} 41.0864$ & $\mathrm{H} 4 \mathrm{CO} 112.41$ & $\mathrm{H} 4 \mathrm{COHO}$ & 180.00 \\
\hline
\end{tabular}


Table 4. Interatomic distances and overlap populations

\begin{tabular}{lclc}
\hline & Reactant $^{a}$ & \multicolumn{1}{c}{ TS $^{\text {b }}$} & Products \\
\hline \hline $\mathrm{AO}-\mathrm{H}^{\mathrm{c}}$ & 0.982 & 1.803 & $\infty$ \\
$\mathrm{S}(\mathrm{OH})^{\mathrm{d}}$ & 0.613 & $0.124(80)$ & 0 \\
$\mathrm{RC}-\mathrm{O}^{\mathrm{c}}$ & 1.268 & $1.220(35)$ & 1.132 \\
$\mathrm{~S}(\mathrm{CO})^{\mathrm{d}}$ & 0.767 & $1.010(37)$ & 1.424 \\
$\mathrm{RC}-\mathrm{C}^{\mathrm{c}}$ & 1.459 & 1.551 & $\infty$ \\
$\mathrm{S}(\mathrm{CC})^{\mathrm{c}}$ & 0.647 & $0.480(26)$ & 0 \\
$\mathrm{RC}-\mathrm{H}^{\mathrm{c}}$ & 2.544 & $1.254(88)$ & 1.085 \\
$\mathrm{~S}(\mathrm{CH})^{\mathrm{d}}$ & -0.004 & $0.229(28)$ & 0.797 \\
\hline
\end{tabular}

a-1

Numbers in parentheses indicate the percentage of the full change in the parameter that has occurred at the MP2 TS.

Interatomic distance.

dOvarlap population.

Methyl $\mathrm{C}-\mathrm{H}$ bonds average 0.777 in $\mathrm{Z}-1$.

in the Mulliken population analysis) between the atoms involved to assess bond breaking and making. Table 4 lists the distances and overlap populations between the atoms involved in bond making and breaking in the MP2 TS for this fragmentation. By the overlap population criterion the TS is characterized more by bond breaking (particularly the $\mathrm{O}-\mathrm{H}$ bond) than by bond making, which is consistent with the high energy of the TS. This result is also in accordance with our understanding of pericyclic reactions [4], which predict that a low energy concerted path should not exist for this process. Attempts to give the reaction a more synchronous character, by reducing the stretching of the $\mathrm{O}-\mathrm{H}$ bond in the TS by decreasing the $\mathrm{CCO}$ bond angle, encountered a puwerful residual force to open this angle in trial structures. This demonstrates that $\mathrm{H}$ transfer and $\mathrm{C}-\mathrm{C}$ bond breaking are highly asynchronous.

At the suggestion of a referee we characterized the TS for this reaction at the RHF level of theory by using the $6-31+G(d, p)$ [the + indicates the presence of diffuse gaussian valence (an $s$ and three $p$ ) functions on the carbons and oxygen] basis set. No TS could be found with our MP2 optimized parameters with this method, because the TS finding algorithm converged on a structure with no negative eigenvalues of the force constant matrix. However with RHF methods we did find a proper TS not too far from the MP2 TS previously discussed, but the RHF TS does not lead to fragmentation like the MP2 TS does. When optimized in the direction of products the HF TS led to formation of a species protonated on one of the $\mathrm{C}-\mathrm{H}$ bonds of the methyl group. This $\mathrm{C}$-protonated acetaldehyde ion (2) is predicted to be stable by RHF theory: it has 18 positive vibrational frequencies. Although we have not shown that this nonclassical structure collapses readily to the formyl ion and methane, it would not be surprising if it did so because it is predicted to lie 146.9 $\mathrm{kJ} / \mathrm{mol}$ higher in energy than the products. The MP2 and RHF methods predict slightly different mechanisms for the fragmentation. The HF-derived mechanism is a stepwise process that passes through 2, its
Table 5. Optimized parameters of the nonclassical ion $2[\mathrm{RHF} / 6-31+\mathrm{G}(d, p]$

\begin{tabular}{|c|c|c|c|c|c|}
\hline \multicolumn{2}{|c|}{ Lengths (Å) } & \multicolumn{2}{|c|}{ Angles (deg) } & \multicolumn{2}{|c|}{ Dihedral angles (deg) } \\
\hline $\mathrm{RC} 10$ & 1.1740 & & & & \\
\hline $\mathrm{RCC}$ & 1.5556 & $\mathrm{CCO}$ & 120.06 & & \\
\hline $\mathrm{RC} 2 \mathrm{Ht}$ & 1.2643 & $\mathrm{HtC} 2 \mathrm{C} 1$ & 83.68 & $\mathrm{H} t \mathrm{CCO}$ & 0.0 \\
\hline $\mathrm{RC} 2 \mathrm{H} 1$ & 1.0830 & $\mathrm{H} 1 \mathrm{C}_{2} \mathrm{C} 1$ & 113.44 & $\mathrm{H} 1 \mathrm{CCO}$ & 113.75 \\
\hline $\mathrm{RC} 2 \mathrm{H} 2$ & 1.2616 & $\mathrm{H} 2 \mathrm{C}_{2} \mathrm{C} 1$ & 122.50 & $\mathrm{H}_{2} \mathrm{CCO}$ & 0.0 \\
\hline $\mathrm{RC} 2 \mathrm{H} 3$ & 1.0830 & $\mathrm{H} 3 \mathrm{C} 2 \mathrm{C} 1$ & 113.44 & $\mathrm{H3CCO}$ & -113.75 \\
\hline $\mathrm{RC} 1 \mathrm{H} 4$ & 1.0872 & $\mathrm{H} 4 \mathrm{C} 1 \mathrm{C} 2$ & 113.63 & $\mathrm{H} 4 \mathrm{CCH} 1$ & -66.25 \\
\hline
\end{tabular}

optimized parameters are given in Table 5. Because Moller-Plesset theory does not necessarily give an upper bound for the energy [12], there is always some possibility that its use to minimize energy will give incorrect results. In this case it is clear that RHF theory reproduces the experimental energies much better than MP2 theory does. This can be taken as evidence that the two-step RHF mechanism is the correct one. The energies of the species involved in this fragmentation are illustrated graphically in Figure 1 along with a picture of the molecule at the RHF TS.

Methane is not eliminated from 1 by an ion-neutral complex-mediated mechanism because the intermediates involved would be too high in energy. Table 6 gives the energies of separated species that might be partners in an intermediate complex. The energies of complexes derived from them depend on the type of neutral involved. If the neutral is nonpolar, as in the first two possibilities, the heat of formation of the complex is typically about $25 \mathrm{~kJ} / \mathrm{mol}$ below that of the separated species [13]. With a polar neutral, such as acetaldehyde in the third example, the complex is about $80 \mathrm{~kJ} / \mathrm{mol}$ below the separated species [14]. The complexes are all at least $150 \mathrm{~kJ} / \mathrm{mol}$ too high to compete with the TS we have found. Thus the hydrogen migrates from $O$ to the methyl carbon without ever becoming free of covalent forces, even though the TS is relatively high in energy.

In 1988 McAdoo [15] reviewed the chemistry of odd-electron carbonyl ions and commented that the low energy reaction paths that characterize longer chain ions are no longer possible when the size of the ion is reduced. The result is that smaller ions decompose by higher energy processes that are bypassed by the longer chain ions. Novel high energy reactions that do not occur under ordinary chemical conditions can be observed and studied in the gas phase by choosing an ion in which the more usual reactions cannot occur. Detailed studies of such reactions thus enlarge our perspectives on chemical reactions and their transition states. The same is true of even-electron ions, an example of which is methane elimination from 1.

The MP2 TS for elimination of $\mathrm{CH}_{4}$ from 1 is similar to that for loss of $\mathrm{H}_{2}$ from protonated formaldehyde [16] in that the HOC bond angle is sharply acute, whereas the HCO bond angle (which 
Table 6. Heats of formation of complexes and their members ${ }^{\mathrm{a}}$

\begin{tabular}{|c|c|}
\hline $\mathrm{CH}_{3}$ & $\overline{146}$ \\
\hline $\mathrm{HCOH}^{+}$ & 962 \\
\hline $\mathrm{HCOH}^{+}+\mathrm{CH}_{3}$ & 1108 \\
\hline$\left[\mathrm{HCOH}^{+}---\mathrm{CH}_{3}\right]$ complex ${ }^{b}$ & 1083 \\
\hline $\mathrm{CH}_{3} \mathrm{CHO}^{+}$ & 821 \\
\hline $\mathrm{H}^{\circ}$ & 218 \\
\hline $\mathrm{CH}_{3} \mathrm{CHO}^{+}+\mathrm{H}$ & 1039 \\
\hline$\left[\mathrm{CH}_{3} \mathrm{CHO}^{+} \ldots \mathrm{H}^{\prime}\right]$ complex & 1014 \\
\hline $\mathrm{CH}_{3} \mathrm{CHO}$ & -40 \\
\hline $\mathbf{H}^{+}$ & 1530 \\
\hline $\mathrm{CH}_{3} \mathrm{CHO}+\mathrm{H}^{+}$ & 1490 \\
\hline$\left[\mathrm{CH}_{3} \mathrm{CHO}--\mathrm{H}^{+}\right]$complex ${ }^{\mathrm{C}}$ & 1410 \\
\hline $\mathrm{CH}_{3} \mathrm{CHOH}^{+}$ & 583 \\
\hline$E_{a}^{d}$ & 264 \\
\hline TS & 847 \\
\hline
\end{tabular}

a From ref 10 unless otherwise designated.

'Separated species minus $25 \mathrm{~kJ} / \mathrm{mol}$ [13].

'Separated species minus $80 \mathrm{~kJ} / \mathrm{mol}$ [14]

Activation energy calculated in this work.

Transition state for loss of methane from 1

corresponds to our $\mathrm{CCO}$ angle) remains obtuse. However the $\mathrm{O}-\mathrm{H}$ bond is less highly stretched in the $\mathrm{CH}_{2} \mathrm{OH}^{+}$TS than in ours, and the hydrogen originally on oxygen remains closer to the oxygen than to the carbonyl carbon, in contrast to the MP2 TS for the loss of $\mathrm{CH}_{4}$ from 1. The TS for loss of $\mathrm{H}_{2}$ from $\mathrm{CH}_{2} \mathrm{OH}^{+}$ more nearly represents transfer of a proton to the atom (in this case a hydrogen on carbon) being lost than to one of its bonds. The TS for elimination of $\mathrm{H}_{2}$ from the odd-electron ethane molecular ion has been studied by both semiempirical [17] and ab initio methods [18]. Both studies found the TS to be highly unsymmetrical. The two hydrogen atoms lost in this reaction originate on separate carbons; however one of the HCC bond angles becomes acute, whereas the other remains obtuse in the TS. In the former study the TS clearly represents the protonation of a $\mathrm{C}-\mathrm{H}$ bond. However there are differences between the $\mathrm{H}_{2}$ loss from $\mathrm{C}_{2} \mathrm{H}_{6}^{+}$ as studied in ref 17 and the reaction discussed in the present work. The TS was found with semiempirical methods, it is the reaction of an odd-electron ion, and the energy of activation and translational energy release are much lower $(54.4$ and $18.4 \mathrm{~kJ} / \mathrm{mol})$ [18] compared to 261.6 and $42.3 \mathrm{~kJ} / \mathrm{mol}$ in the methane loss from 1. Insufficient details of the TS structure are given in the ab initio paper [19] to determine whether the hydrogen with an acute HCC bond angle is closer to the carbon from which it started or to the other carbon. Thus the ab initio study neither confirms nor refutes that the TS for $\mathrm{H}_{2}$ loss from ionized ethane is well described as the protonation of a bond. Nevertheless the transition state we characterize here appears to belong to a general type for high energy 1,2 eliminations that involve the loss of proton transfer to the group.

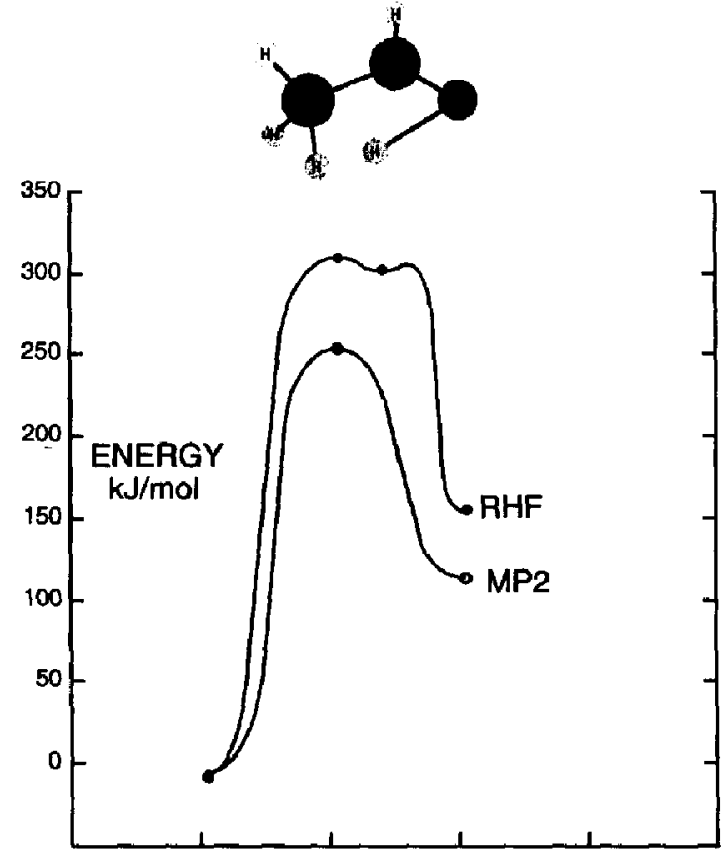

Figure 1. Potential energy surface for the loss of methane from protonated acetaldehyde as calculated by RHF and MP2 methods. The RHF transition state is shown at the top.

Methane elimination from 1 may be related to a reaction of considerable practical importance-catalytic cracking. It is well established that protonation of alkanes can lead to fragmentation by loss of a smaller alkane both in the gas phase [20] (although loss of $\mathrm{H}_{2}$ may be more prominent) and in solution [21].

\section{Acknowledgments}

We gratefully acknowledge the financial support of the Robert A. Welch Foundation (grant H-609), The University of Texas Center for High Performance Computing for a generous allocation of computer time, the National Institutes of Health Minority High School Student Research Apprentice Program, and Debbie Pavlu for assistance with typing.

\section{References}

1. (a) McAdoo, D. J.; Traeger, J. C.; Hudson, C. E.; Griffin, L. L. J. Phys. Chem, 1988, 92, 1524; (b) Traeger, J. C.; Hudson, C. E.; McAdoo, D. J. J. Phys. Chem. 1990, 94, 5714; (c) McAdoo, D. J.; Hudson, C. E.; Traeger, J. C.; Grose, A.; Griffin, L. L. J. Am. Soc. Mass Spectront. 1991, 2, 261.

2. (a) Wendelboe, J. F.; Bowen, R. D.; Williams, D. H. I. Am. Chem. Soc. 1981, 103, 2333; (b) McAdno, D. J.; Hudson, C. E. Rapid Commun. Mass Spectrom. 1991, 5, 357.

3. (a) Hudson, C. E.; McAdoo, D. J. Int. 1. Mass Spectrom. Ion Processes 1984, 59, 325; (b) Traeger, J. C.; Hudson, C. E.; McAdoo, D. J. J. Phys. Chem. 1988, 92, 1519; (c) Heinrich, N.; Louage, F.; Lifschitz, C.; Schwarz, H. f. Am. Chem. Soc. 1988, 110, 8183; (d) Hudson, C. E.; Ahmed, M. S.; Olivella, S.; Ciam, C. S.; McAdoo, D. J. Org. Mass Spectrom. 1992, 27, 435.

4. (a) McAdoo, D. J. Mass Spectrom. Rev. 1988, 7, 363; (b) McAdoo, D. J.; Morton, T. H. Acc. Chem. Res. 1993, 26, 295. 
5. Hoffman, R.; Woodward, R. B. J. Am. Chem. Soc. 1965, 87, 2046.

6. Shannon, T. W.; McLaferty, F. W. J. Am. Chem. Soc. 1966, 88, 5021-5022.

7. Keyes, B. G.; Harrison, A. G. Org. Mass Spectrom. 1974, 9, 221.

8. Frisch, M. J; Trucks, G. W.; Head-Gordon, M.; Gill, P. M. W.; Wong, M. W.; Foresman, J. B.; Johnson, B. G.; Schlegel, H. B.; Robb, M. A.; Replogle, E. S.; Gomperts, R.; Andres, J. L.; Raghavachari, K.; Binkley, J. S.; Gonzales, C.; Martin, R. L; Fox, D. J.; Defrees, D. J.; Baker, J.; Stewart, J. J. P.; Pople, J. A. GAUSSIAN 92, revision B, Gaussian, Inc., Pittsburgh, PA, 1992.

9. Bowen, R. D.; Williams, D. H.; Hvistendahl, G. I. Am. Chem. Soc. $1977,99,7509$.

10. Bowen, R. D.; Williams, D. H.; Schwarz, H. Angew. Chem. Int Ed. Engl. 1979, 18, 451.

11. Lias, S. G.; Bartmess, J. E.; Liebman, J. F.; Holmes, J. L.; Levin, R. D.; Mallard, W. C. J. Phys. Chem. Ref. Data 1988, 17, Suppl. 1.
12. Hehre, W. J:; Radom, L.; Schleyer, P. v. R.; Pople, J. A. $A b$ Initio Molecular Orbital Theory; Wiley-Interscience: New York, 1986; $\mathrm{p} 40$.

13. Hudson, C. E.; McAdoo, D. J. Int. J. Mass Spectrom. Proc. 1984, 59,325 .

14. MrAdoo, D. J.; Hudson, C. F. Org. Mass Spectrom. 1986, 21, 779.

15. McAdoo, D. J. Org. Mass Spectrom. 1988, 23, 350.

16. Uggerud, E.; Helgaker. T. J. Am Chem. Soc. 1992, 114, 4265.

17. Dewar, M. J. S.; Rzepa, H. S. J. Am. Chem. Soc, 1977, 99, 7432.

18. Hvistendahl, G.; Williams, D. H. I. Chem Soc. Perkin Trans. 2 1975,881 .

19. Brăten, S. M.; Helgaker, T; Uggerud, E.; Vulpius, T. Org. Mass Spectrom. 1993, 28, 1262.

20. Futrell, J. H.; Abrahamson, A. P.; Battacharya, A. K.; Tiernan, T. O. I. Chem. Phys. 1970, 52, 3655.

21. Olah, G. A.; Klopman, G.; Schlosberg, R. H. J. Am. Chem. Soc. 1969, $91,3261$. 